\title{
Microstructural and Finite Element Analysis - Assisted Nanomechanical Characterization of Maize Starch Nanocomposite Films
}

\author{
G. Mansour ${ }^{a}$, M. Zoumaki ${ }^{a}$, K. Tsongas ${ }^{a}$, D. Tzetzis ${ }^{\text {* }}$ \\ ${ }^{a}$ Aristotle University of Thessaloniki, Department of Mechanical Engineering, Greece \\ ${ }^{b}$ International Hellenic University, School of Science and Technology, Greece
}

Received: September 7, 2020; Revised: December 10, 2020; Accepted: February 7, 2021

\begin{abstract}
Biocomposite films were prepared using normal maize starch plasticized with glycerol and water and sodium montmorillonite clay particles employing the solution mixing procedure. Scanning electron microscopy (SEM), X-ray diffraction (XRD), three-dimensional profilometry and tensile along with nanoindentation tests assisted with a Finite Element Analysis (FEA) were used for the assessment of starch-based films with various percentages of nanoclay particles. XRD analysis revealed intercalation of the test specimens while their morphology was ascertained using SEM/EDX. The FEA results were compared with the experimental measurements from nanoindentation and tensile tests. A satisfactory correlation was obtained between the experimental measurements and the computational models, demonstrating FEA-assisted nanoindentation as a useful technique for assessment, showing the effect of the different nanoclay concentrations on the mechanical properties.
\end{abstract}

Keywords: Biodegradable Nanocomposites, Nanoindentation, Finite Element Analysis, Mechanical Properties, Starch, Nanoclays.

\section{Introduction}

In recent decades, there is an ongoing intensive research concerning the development of advanced materials and their applications, using nano-reinforcements for the enhancement of polymeric, metallic and ceramic matrices to improve their mechanical, thermal and physical properties ${ }^{1-10}$. In the polymer industry, there is an increasing interest in the development of new plastic materials based on natural biodegradable polymers, such as starch and cellulose and its derivatives in combination with nanoadditive materials, capable of replacing, at least in part, the synthetic polymers derived from non-renewable sources such as petroleum ${ }^{11-14}$. Starch, as a very promising natural biopolymer, has considerable advantages since it derives from renewable sources, it is fully biodegradable and has low production cost on an industrial scale that makes it an attractive choice in a wide variety of applications, such as the production of bioplastic and novel construction materials ${ }^{12,13,15}$. In its native granular form, starch is composed of a mixture of two homopolysaccharides; amylopectin an extensively branched macromolecule and amylose, an essentially linear (helical) polymer, which is responsible for the film-forming property of $\operatorname{starch}^{16}$. The development of maize starch-based films with application as alternative materials which is mainly used in packaging industries is considered important in reducing the environmental problems associated with the accumulation of synthetic, nonbiodegradable plastic materials in the environment ${ }^{12}$. However, the use of starch as the polymer matrix for the production of the maize starch-based films, is limited due to its rather poor mechanical performance, compared to traditional synthetic

*e-mail: d.tzetzis@ihu.edu.gr plastic materials. In many cases, nano-fillers, such as clay, are incorporated into the thermoplastic starch matrix to improve mechanical and dynamic properties of the conventional starch films, produced with glycerol $(\mathrm{G})$ and water as plasticizer. Mechanical properties of maize starch films are influenced by glycerol and clay contents. Both glycerol and water act as a typical plasticizer in starch films; with decreasing glycerol concentration, films presented better tensile properties than films with higher glycerol conten ${ }^{16}$. Starch-based conventional films have disadvantages associated with their hydrophilic character and deficient mechanical properties. The addition of definite amount of natural materials such as nanoclays induces significant reinforcing effects in starch films. More specifically, embedding reinforcing materials such as sodium montmorillonite clay (NaMMT) in the starch polymer matrix, can greatly improve physical and mechanical properties of gelatinized $\operatorname{starch}^{16-18}$.

Consistent and precise mechanical testing is critical for the development of starch-based nanocomposite conventional films. The instrumented indentation technique is a promising alternative to conventional measurement methods of mechanical properties of materials, because of its various advantages such as minimal nondestructive specimen preparation, high spatial resolution, and easy test procedures ${ }^{19-22}$. The most important feature of an indentation measurement is the capability to provide detailed information from a high local deformation. In materials engineering, such technique, apart from the local characterization of the material, has been also widely used in the literature to estimate the bulk material elastic properties by combining the experimental indentation curves with Finite Element Analysis (FEA) 
simulation modeling of indentation experiments ${ }^{4,7}$. Also, in another work the nanoindentation experiments on thin films alongside FEA have shown very good correlation results ${ }^{23}$.

In this study, the instrumented indentation technique was used to examine the effectiveness of a non-destructive methodology for the evaluation of mechanical properties of bio-based material films. A series of maize starch-based nanocomposite films with different compositions were fabricated by varying the concentrations of glycerol and sodium montmorillonite and the mechanical performance, as a function of clay and plasticizer contents, of the conventional composite and nanocomposite films was characterized by an instrumented nanoindentation technique at room temperature, and the values were compared with the tensile test results. The results obtained from the experimental investigation and analysis of mechanical properties of the films were then compared with a developed Finite Element Analysis (FEA) model simulating the nanoindentation experiment. The satisfactory correlation exhibited a very promising nondestructive technique for this type of materials.

\section{Materials and methods}

\subsection{Fabrication of maize starch-based nanocomposite films}

Previous studies demonstrated that the unmodified clays such as NaMMT showed better mechanical properties than the organically modified clay. This tensile behavior can be attributed to better dispersion of NaMMT clay particles in the starch matrix mainly due to the higher hydrophilicity of sodium ion compared to the organically modified clay ${ }^{24-26}$. In this study, conventional composite and nanocomposites films of plasticized maize starch were prepared by a solution mixing procedure with glycerol/water plasticizer containing NaMMT clay as reinforcing filler ${ }^{18,24}$. The sodium montmorillonite clay with a CEC (cation exchange capacity) of $92.6 \mathrm{meq} / 100 \mathrm{~g}$ clay was supplied by Southern Clay
Products, Inc., Texas USA. A commercial normal maize starch containing approximately $21-23 \%$ amylose (supplied by Nestlẻ Hellas, Greece) was used in the experiments. The moisture content of starch was 11-12 wt $\%$ as determined by drying to constant mass. Glycerol was supplied by Mallinckrodt Chemical Works, USA.

The plasticized starch films were prepared by the following solution mixing procedure: The maize starch was dispersed in distilled water containing different levels of glycerol (as a plasticizer) and the suspension was stirred at $80^{\circ} \mathrm{C}$ for half an hour to gelatinize the starch. A clay suspension was homogenized at room temperature in distilled water and then added to the gelatinized starch. The mixture (where the starch concentration of the solution was $6.5 \mathrm{wt} \%$ ) was stirred at $90{ }^{\circ} \mathrm{C}$ for another half an hour. Films were obtained by casting the hot mixture into teflon plates (100 $\mathrm{mm} \times 120 \mathrm{~mm}$ ) and dried in an air-circulating oven at $45^{\circ} \mathrm{C}$ for approximately $24 \mathrm{~h}$. Finally, the films were stored under controlled conditions of temperature $\left(\approx 22-24^{\circ} \mathrm{C}\right)$ and relative humidity $(\approx 52-55 \%$ ) for one week prior to testing. The glycerol content of conventional and nanocomposite films was varied between $20 \mathrm{wt} \%(\mathrm{G} 20)$ and $30 \mathrm{wt} \%$ (G30) with clay amounts of $0 \mathrm{wt} \%$ (NaMMT0), 10wt\% (NaMMT10) and $20 \mathrm{wt} \%$ (NaMMT20), based on the amount of dry starch. The prepared films which are shown in Figure 1, were macroscopically isotropic, homogeneous, smooth and flexible, with thickness of about 0.1 to $0.15 \mathrm{~mm}$ and thickness homogeneity of about $0.01 \mathrm{~mm}$.

\subsection{Tensile tests}

Tensile tests were used to evaluate the elastic modulus, tensile strength and elongation at break of maize starchbased conventional composite and nanocomposite films. ASTM D882 27 test method of thin plastic sheeting was used to determine the tensile properties of the composite film samples. Tensile properties were measured using a TA.XT Plus texture analyzer (Stable Micro Systems Ltd, UK) with cross head speed of $20 \mathrm{~mm} / \mathrm{min}$. For each sample in total 20 replicate films were measured.
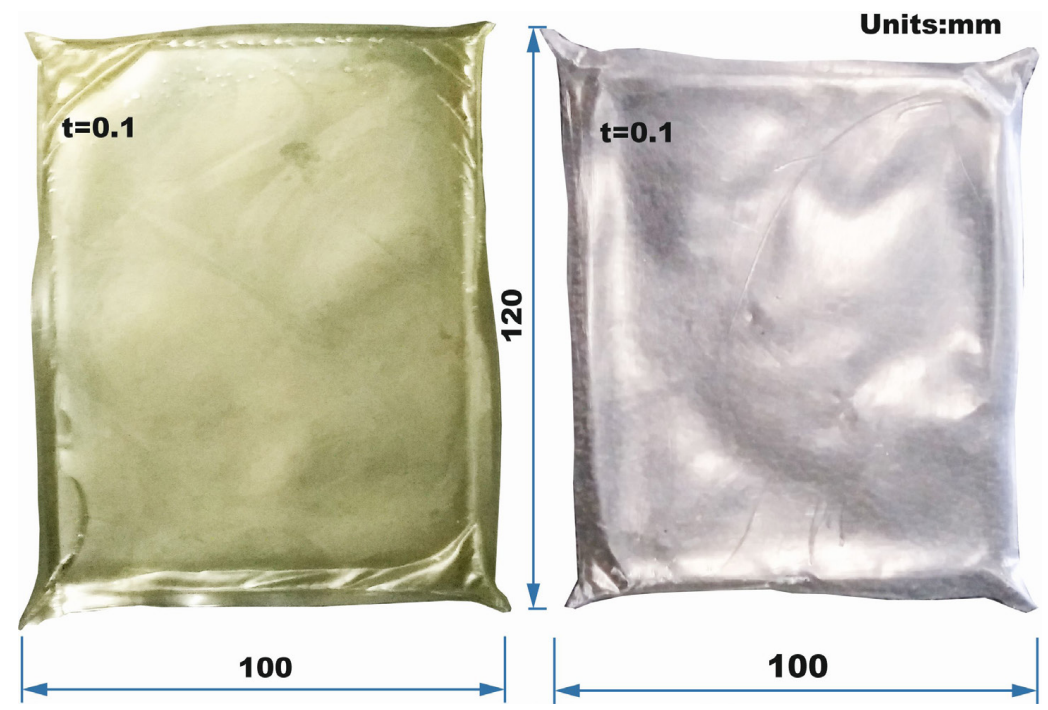

Figure 1. Photographs of the conventional (left) and NaMMT nanocomposite (right) maize starch-based films. 


\subsection{Morphological characterization methods}

The morphological features of the specimens were assessed through a Phenom ProX (Thermo-Fisher Scientific, MA USA) instrument, equipped with an optical microscope with a magnification range of $20-135 \mathrm{x}$ and a scanning electron microscope (SEM) with a thermionic CeB6 source, as well as a fully integrated Energy Dispersive Spectrometer (EDS) detector. The specimens were attached on a metal stub with double sided carbon tape (Ted Pella, USA) and inserted in the scanning electron microscopy's vacuum chamber using a special charge reduction sample holder. The sample holder is designed to reduce sample charging and eliminate extra sample preparation of non-conductive samples. The dedicated software package ProSuite PC (Thermo-Fisher Scientific, MA USA) was used for the instrument control. Also, an optical (confocal) 3D measurement Nano-Focus $\mu$ surf system (Oberhausen, Germany) was used to capture in detail the topography of the maize starch nanocomposite samples.

\subsection{X-ray diffraction}

The obtained nanocomposite structure of films was ascertained by X-ray diffraction (XRD) analysis. The XRD measurements were performed using a Panalytical X'Pert Pro Multipurpose Diffractometer in the diffraction 2-theta angle range of $2-30^{\circ}$ (in $0.01^{\circ}$ steps) to investigate the structural properties of starch and sodium montmorillonite clay in their pure form and samples of maize starch nanocomposite films with different contents of glycerol and clay. The interlayer $\mathrm{d}$-spacing of the silicate layers was calculated from the peak position in XRD patterns using the Bragg equation.

\subsection{Nanoindentation tests}

The nanoindentation tests were conducted on a DUH-211S Shimadzu (Kyoto, Japan) device, with a load resolution of $0.196 \mu \mathrm{N}$. The indenter that was used is a Berkovich diamond tip (with a tip radius less than $100 \mathrm{~nm}$ ). A number of points was selected through an optical microscope and these were strategically scattered on the surface of the films. In the current work, at least ten measurements were performed for each nanocomposite maize starch film.

The indenter is initially driven toward and then contacts the surface of each film, at a constant loading rate of $3.5 \mathrm{mN} / \mathrm{s}$, until a peak force of $20 \mathrm{mN}$. Afterwards, the indenter was unloaded with the same rate. The maximum force has been held for $5 \mathrm{~s}$ (in order to reduce the effect of viscoelastic deformation of the specimens) and then the indenter was unloaded, to a value of zero.

The indentation hardness and modulus values of the maize starch nanocomposite films were determined based on the calculation method of Oliver and Pharr ${ }^{28}$. The hardness can be calculated as a function of the maximum penetration depth of the indentation:

$H=\frac{P_{\max }}{A}$

where $P_{\max }$ is the maximum applied load measured at the maximum depth of penetration $\left(h_{\max }\right), A$ is the projected contact area between the indenter and the film. For a perfect
Berkovich indenter, $A$ can be expressed as a function of the contact indentation depth $h_{\mathrm{f}}$ as:

$$
A=3 \sqrt{3} h_{f}^{2} \tan ^{2} 65=23.96 h_{f}^{2}
$$

The contact indentation, $h_{\mathrm{f}}$, can be determined from the following expression:

$h_{f}=h_{\max }-\varepsilon \frac{P_{\max }}{S}$

where $\varepsilon$ is a geometric constant $\varepsilon=0.75$ for a pyramidal indenter, $S$ is the contact stiffness which can be determined as the slope of the unloading curve at the maximum loading point, i.e.

$S=\left(\frac{d P}{d h}\right)_{h=h_{\max }}$

The reduced elastic modulus $E_{\mathrm{r}}$ is given by:

$E_{r}=\frac{S}{2 \beta} \sqrt{\frac{\pi}{\mathrm{A}}}$

where $\beta$ is a constant that depends on the geometry of the indenter. For the Berkovich indenter, $\beta=1.034$. The specimen elastic modulus $\left(E_{\mathrm{s}}\right)$ can then be calculated as:

$\frac{1}{\mathrm{E}_{r}}=\frac{1-v_{s}^{2}}{E_{s}}+\frac{1-v_{i}^{2}}{E_{i}}$

where $\mathrm{E}_{i s}$, and $v_{i s}$ are the elastic modulus and Poisson's ratio, respectively, for the indenter and the specimen. For a diamond indenter, $E_{i}$ is $1140 \mathrm{GPa}$ and $v_{i}$ is 0.07 .

The specimen's hardness $H$ and elastic modulus $E_{s}$ were obtained from the set of equations given above.

\section{FEA Simulation of the Nanoindentation Measurements}

The nanoindentation experimental results were simulated utilizing a FEA-based procedure with the commercial code ANSYS. In order to define the interface between the Berkovich indenter and the surface of the nanocomposite samples contact elements have been used (Figure 2). Previous work ${ }^{4,7,29}$ has shown that the contact element stiffness and friction coefficient in a large range of their values do not affect the evaluation results. Kinematic hardening leads to a rapid convergence in the corresponding FEA calculations, so this method was applied in the developed procedure.

The nanoindentation curves have been generated considering two load steps. The first load step simulated the loading stage of the indenter into the nanocomposites. The second step, which can be called as the relaxation stage the indenter was removed leading to the material elasticplastic recovery. Assumptions of initial material values for the tangent moduli $E_{\mathrm{i}}$ of the multilinear stress-strain curves of the samples were made in the FEA model. An experimental indentation depth is applied to the indenter of the FEA model and the corresponding force reaction is determined and compared to the measured value. If the 
(a)

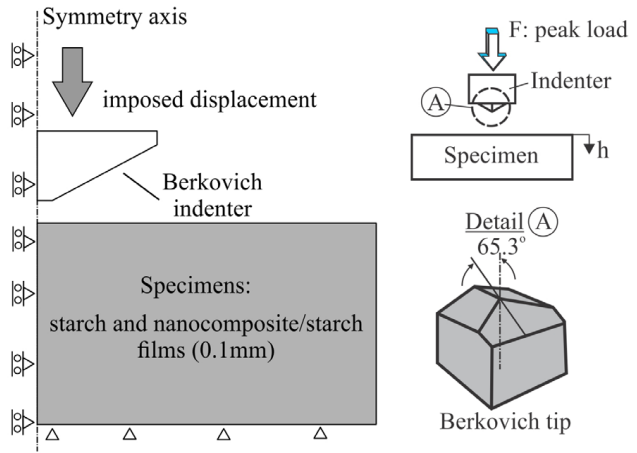

(b)

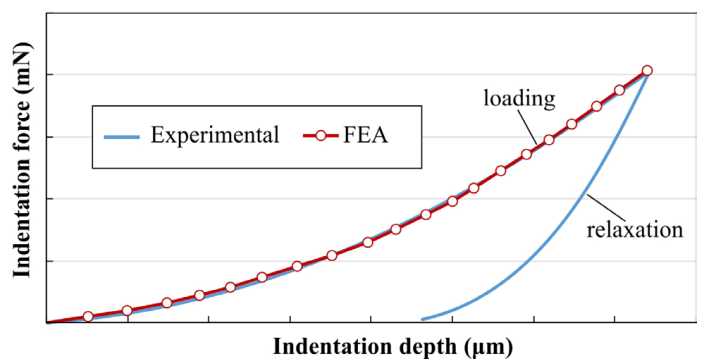

Figure 2. Schematic procedure of (a) the Finite Element Model of the nanoindentation testing simulation and (b) curve-fitting of the nanoindentation measurements by computationally generated indentation data

FEA does not converge with and experimental force, then the value of the tangent modulus is approximated again and the FEA solution is repeated. Where the FEA force fits the indentation force the value of the tangent modulus is considered converged and the next values of force-depth are applied to the model. The next calculation step starts with the previous indentation depth, considering the existing stress status as well as the previously obtained tangent modulus. This procedure is repetitive until the last pair of force-depth values has converged and the loop ends. In this work, 20 steps of simulation have been considered adequate for the curve fitting of the nanoindentation curves.

\section{Results and Discussion}

\subsection{Tensile test results and morphology}

The influence of different levels of glycerol concentration and NaMMT clay content is presented in the typical tensile stress-strain curves of the conventional composite and nanocomposite starch-based films are as illustrated in Figure 3. It can be seen from the graphs and the values in Table 1 that increasing glycerol content resulted in a decrease in tensile strength and an increase in the elongation at break. Lower glycerol concentrations were generally associated with higher mechanical strength (and Young's modulus) and lower elongation at break than higher levels of glycerol concentration. Also the tensile properties of the films were enhanced through the addition of NaMMT clay even at lower contents. It becomes apparent from this study that the combined addition of glycerol and NaMMT clay in the starch polymer matrix resulted in a pronounced reinforcement of the mechanical properties of the films. The mechanical properties of starch nanocomposite films are highly related to their microstructure which in turn is related to the incorporation of natural materials such as nanoclays into polymeric systems ${ }^{17,30}$. Similar results were obtained in previous work, where the composites were prepared by using regular cornstarch plasticized with glycerol and reinforced with hydrated kaolin ${ }^{31}$.

The structural properties and morphology of starch-based nanocomposite films and the level of dispersion of the fillers in the starch polymer matrix were investigated by scanning electron microscopy (SEM) coupled with an energy dispersive spectroscopy (EDX). The biodegradable films prepared in this study were developed by incorporation of nanoclay particles into the thermoplastic starch matrix at a nanoscale level and formed a nanocomposite structure ${ }^{18,24}$. SEM micrographs with the x-ray mapping analysis of the cross section of films containing different glycerol and clay contents (Figure 4a-c) revealed that the surfaces of the membranes were continuous without noticeable pores, cracks, breaks or interruptions with homogeneous distribution of clay platelets in the plasticized starch matrix. Similar morphology and homogeneous clay distribution were observed in all conventional composite and nanocomposite samples analysed from each film.

Montmorillonite (MMT) is a clay mineral that consists of stacked silicate sheets with thickness of about $1 \mathrm{~nm}$ and a few hundred nanometers in width and length. Montmorillonite has a structure consisting of an octahedral aluminum or magnesium oxide sheet that is sandwiched between two tetrahedral silicon oxide layers. The interlayer galleries of MMT are normally occupied by metal ions such as $\mathrm{Na}^{+}, \mathrm{Li}^{+}, \mathrm{Mg}^{2+}$ and $\mathrm{Ca}^{2+}$ that can be replaced by various organic cations such as quaternary ammonium forming the organically modified montmorillonite clay. Therefore, the uniform dispersion of clay particles in the nanocomposite films was also confirmed by the good dispersion of $\mathrm{Si}, \mathrm{Al}, \mathrm{Na}$ and $\mathrm{Mg}$ in polymer matrices (as shown in EDX mapping images in Figure 4a-c). The structure and morphology of montmorillonite and the exchangeable cations in the interlayer space of MMT are responsible of many fundamental properties of the clays including cation exchange capacity and specific surface area ${ }^{24}$. Additionally, the above results support the conclusion that the incorporation of clay platelets into the starch polymer matrix over the range of clay concentrations up to $10 \mathrm{wt} \%$ has formed a more compact structure that improved the mechanical properties of the nanocomposite films. However, SEM analysis revealed an inhomogeneous distribution of clay in the starch matrix with significant aggregation of nanoparticles occurred at higher clay loading levels (20 wt \%) that resulted in brittle and relatively stiff films.

Native maize starch displayed a typical A-type crystalline structure and characteristic diffraction peaks (in the XRD pattern) with strong reflections at $2 \theta$ angles of about $15^{\circ}$ and $23^{\circ}$ and a double peak at $17^{\circ}$ and $18^{\circ}$, as illustrated in Figure $5 \mathrm{a}$. The conventional films of thermoplastic maize starch containing 20 and $30 \mathrm{wt} \%$ glycerol concentrations exhibited a mixture of typical V- and B-type crystalline X-ray diffraction patterns, as well as the characteristic diffraction peaks (in the XRD spectra) with strong reflections at $2 \theta$ angles of about $17.3^{\circ}, 19.7^{\circ}$ and $22.2^{\circ}$. 
Table 1. Mechanical properties (tensile strength, elongation at break and elasticity modulus) of the tested films.

\begin{tabular}{|c|c|c|c|c|c|c|}
\hline \multirow{2}{*}{ Specimen } & \multicolumn{2}{|c|}{ Tensile Strength } & \multicolumn{2}{|c|}{ Elongation at break } & \multicolumn{2}{|c|}{ Young's Modulus } \\
\hline & $(\mathrm{MPa})$ & $\mathrm{SD}$ & $\%$ & SD & $(\mathrm{MPa})$ & SD \\
\hline G20-NaMMT0 & 38.98 & 4.01 & 20.17 & 3.36 & 1073.74 & 278.87 \\
\hline G30-NaMMT0 & 12.19 & 2.93 & 36.86 & 2.13 & 451.41 & 163.02 \\
\hline G20-NaMMT10 & 60.51 & 1.40 & 6.00 & 0.80 & 2011.45 & 311.59 \\
\hline G20-NaMMT20 & 37.16 & 10.75 & 2.34 & 1.07 & 870.39 & 346.43 \\
\hline G30-NaMMT10 & 18.48 & 3.63 & 16.83 & 10.44 & 585.33 & 152.63 \\
\hline
\end{tabular}

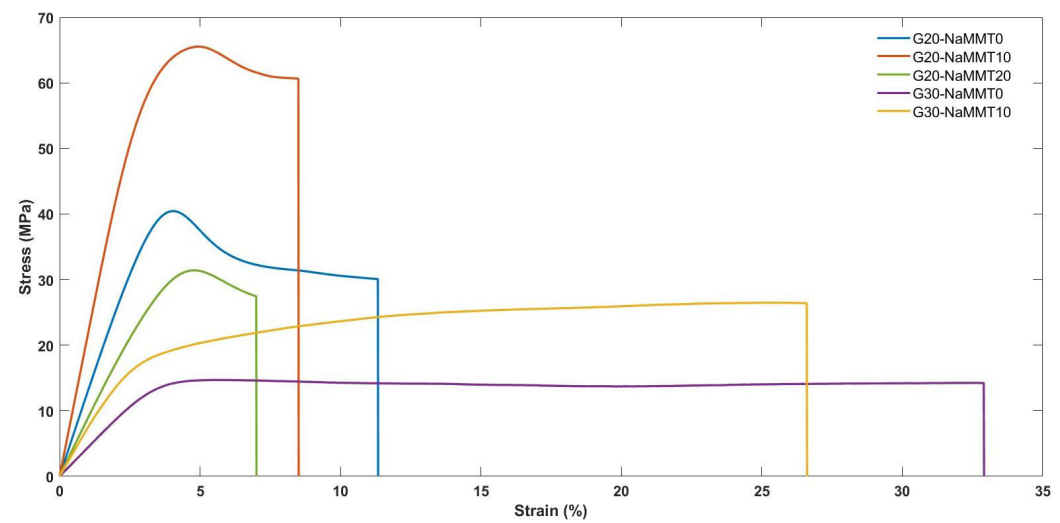

Figure 3. The regression stress-strain curves for the conventional and nanocomposite films G20-NaMMT0, G20-NaMMT10, G20-NaMMT20, G30-NaMMT0 and G30-NaMMT10 with 20 and $30 \mathrm{wt} \%$ glycerol concentrations, with different contents of nanoclay 10 and $20 \mathrm{wt} \%$ respectively.

The XRD peak intensity was further investigated as a function of the scattering angle $(2 \theta)$ of the studied composites for different mass fractions of glycerol and clay ( $\mathrm{g}$ of glycerol and clay $/ 100 \mathrm{~g}$ of dry starch). In Figure $5 \mathrm{~b}$ the XRD pattern of NaMMT clay exhibits an intense diffraction peak at around $7.3^{\circ}$, corresponding to an interlayer basal spacing of $1.21 \mathrm{~nm}$, while the starch XRD pattern does not show any characteristic peak (in the studied range of $2 \theta \approx 2^{\circ}-10^{\circ}$ ). As can be seen from Figure $5 \mathrm{~b}$ the maize starch nanocomposite films prepared with 10 and $20 \mathrm{wt} \%$ of NaMMT clay (with the addition of $20 \mathrm{wt} \%$ glycerol) show a shift in XRD peak towards lower diffraction angles than the pure sodium montmorillonite clay, indicating a significant increase in interlayer spacing of silicate layers $(\approx 1.80 \mathrm{~nm})$. It is therefore evident that the shifting of XRD patterns towards lower angles indicates an intercalated nanocomposite structure $^{17,30,31}$, where water molecules, polymer starch chains and glycerol molecules are incorporated between the silicate layers and as a result, the gallery spacing increases during the intercalation process. However, because of their small size, the penetration of glycerol and water molecules into the silicate layers is favored over the macromolecules of starch. In the case of maize starch nanocomposite films with higher filler content (20 wt \%), the broad small peak in the XRD pattern is probably due to the tendency of nanofillers to aggregate in the starch polymer matrix. The samples of nanocomposites prepared with $20 \mathrm{wt} \%$ glycerol and $10 \mathrm{wt} \%$ of sodium montmorillonite clay exhibited the best mechanical properties from all other samples, where the formation of an intercalated nanocomposite structure was identified in the XRD pattern (G20 wt $\%$ - NaMMT $10 \mathrm{wt} \%$ in Figure $5 b$ ). On the other hand, the mechanical properties of nanocomposite films with higher filler content ( $20 \mathrm{wt} \%$ ) deteriorated, where the formation of a broad small peak was identified in the XRD pattern indicating that the intercalation was not uniform (G20 wt \% - NaMMT $20 \mathrm{wt} \%$ in Figure 5). From the above results, it can be concluded that the mechanical properties of nanocomposite films obtained in this study are in good agreement with the $\mathrm{XRD}$ analysis.

Figure 6 shows the results from the 3D surface topography study of the films to further study their physical properties using the Nanofocus $\mu$ surf instrument with further image processing with Matlab software. The results clearly illustrate that the films presented a relatively smooth surface with low average and RMS (root mean square) surface roughness values, as shown in Figure 7. These findings are also consistent with previous work ${ }^{32-34}$. However, the surface roughness values exhibited a slight decrease with increasing NaMMT clay content. This improvement of surface roughness can probably be explained by the previously shown SEM micrographs in Figure 4, which showed that the incorporation of clay nanoparticles into the starch polymer matrix has formed a more compact structure with a smooth surface of films.

For the samples with $20 \mathrm{wt} \%$ concentration of glycerol the surface roughness values were decreased with increasing sodium montmorillonite clay from 0 to $10 \mathrm{wt} \%$ (based on the amount of dry starch). However, higher concentrations of clay (20 wt $\%$ ) caused significant clay particle aggregation, and thus increased the surface roughness, as also illustrated in Figure 7. In the case of the conventional composite samples with $30 \mathrm{wt} \%$ of glycerol concentration the surface roughness value is at the same level with the conventional 

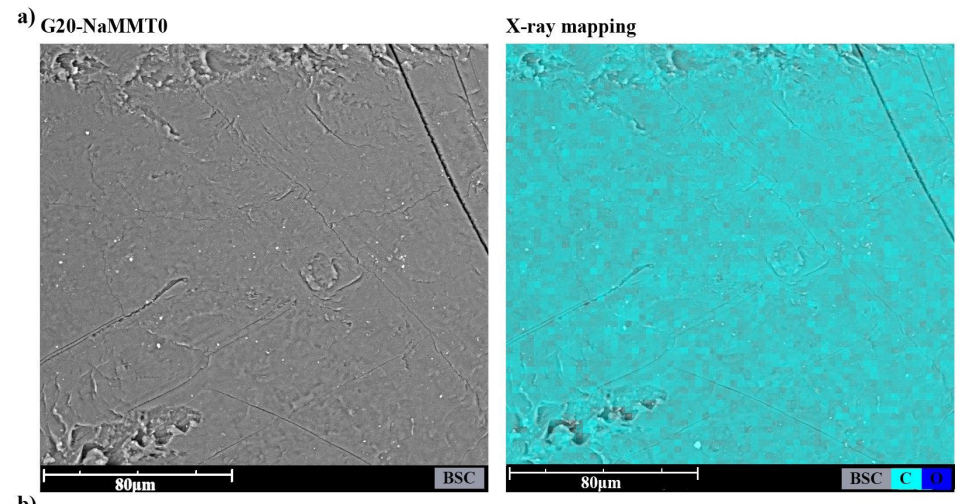

b) G20-NaMMT10

X-ray mapping
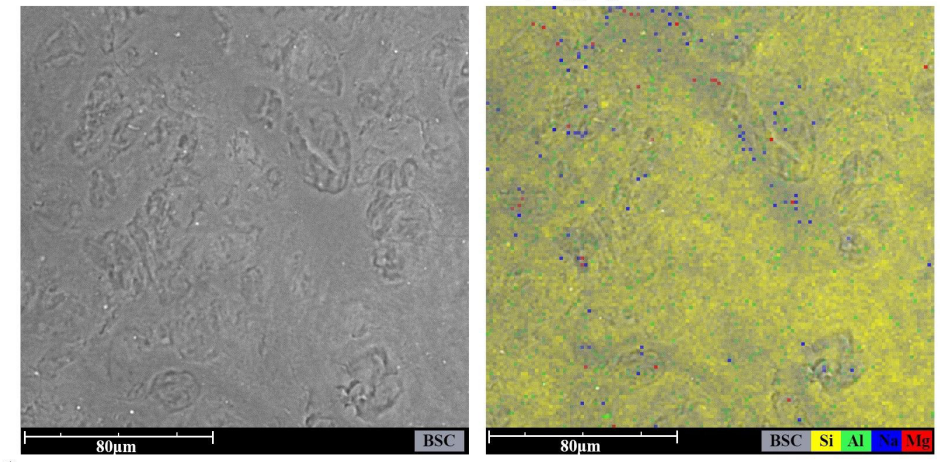

c) G20-NaMMT20

X-ray mapping
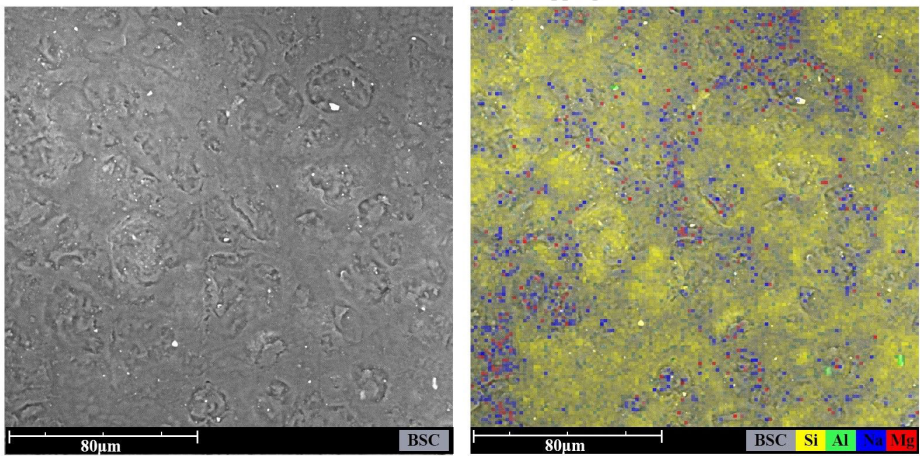

Figure 4. Scanning electron micrographs of representative starch - based films: (a) G20-MT0 conventional composites with $20 \mathrm{wt} \% \mathrm{glycerol}$ concentration, (b) G20-F10 nanocomposites containing $10 \mathrm{wt} \%$ NaMMT clay with $20 \mathrm{wt} \%$ glycerol concentration and (c) G20-MMT20 nanocomposites containing $20 \mathrm{wt} \%$ NaMMT clay with $20 \mathrm{wt} \%$ glycerol concentration.

a)

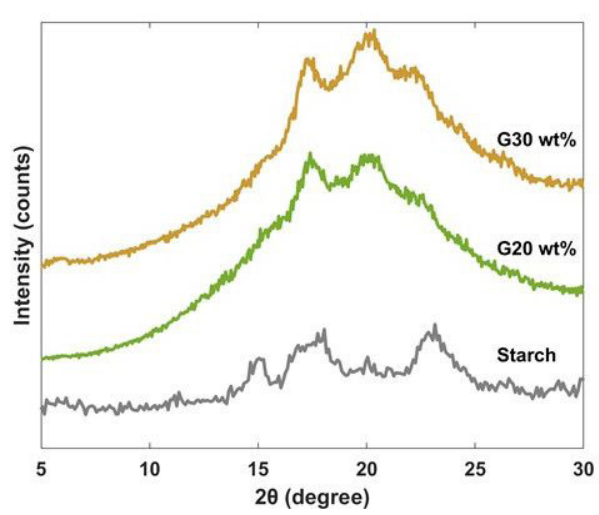

b)

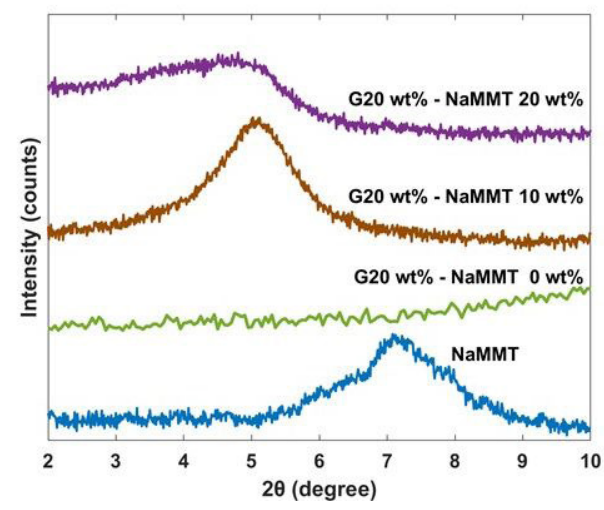

Figure 5. XRD diffraction patterns of (a) maize starch and conventional composites G 20 and G30 with 20 and 30 wt $\%$ glycerol concentrations, respectively, and (b) NaMMT (Ma) and G20-Ma0, G20-Ma10, G20-Ma20, nanocomposites containing 0, 10 and $20 \mathrm{wt} \% \mathrm{NaMMT}$ Ma clay, respectively, with $20 \mathrm{wt} \%$ glycerol concentration. 
a

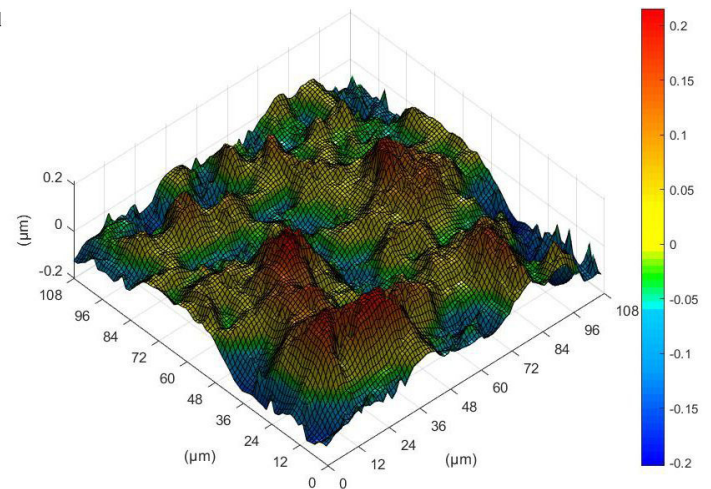

b

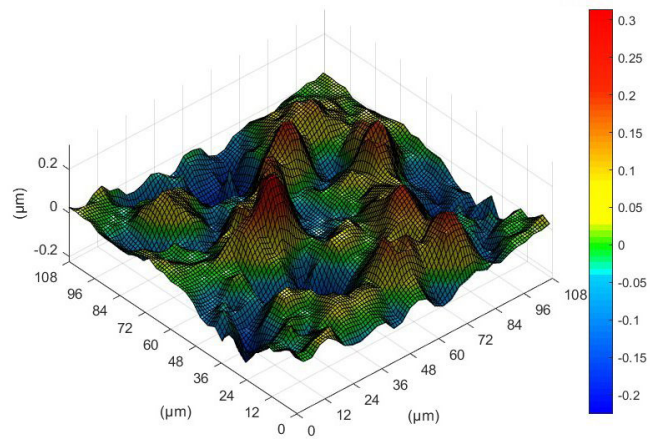

Figure 6. Typical 3D surface topography processed in Matlab of samples with) a G20-NaMMT10 b) G20-NaMMT20

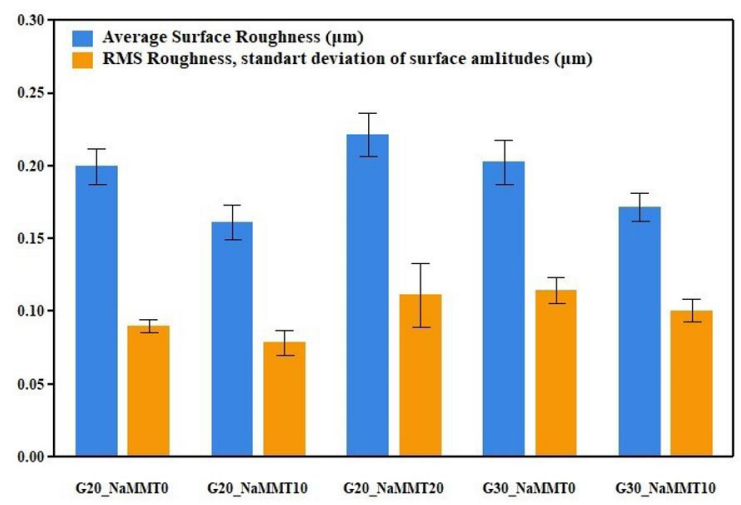

Figure 7. Histogram of average surface roughness and RMS roughness for representative conventional composite and nanocomposite starchbased films with different glycerol and clay contents.

composite samples with $20 \mathrm{wt} \%$ glycerol concentration, when the surface roughness values again decreased with increasing sodium montmorillonite clay from 0 to $10 \mathrm{wt} \%$. However, the samples with $30 \mathrm{wt} \%$ glycerol concentration exhibited higher values of RMS surface roughness and standard deviation compared to those with $20 \mathrm{wt} \%$ glycerol concentration.

\subsection{Nanoindentation test and FEA results}

Initially, stepped nanoindentation was performed in order to determine the optimal indentation force for starch nanocomposite. For a 10 step analysis the value of elasticity modulus has been converged at $20 \mathrm{mN}$ and all the experiments were performed at this peak indentation force. The addition of sodium montmorillonite clay up to $10 \mathrm{wt} \%$ improved the hardness and elastic modulus of the films, as shown in Figure 8. For the G20-NaMMT0 conventional composites the hardness and modulus of elasticity from nanoindentation tests were $82.5 \mathrm{MPa}$ and $810 \mathrm{MPa}$, respectively. By the incorporation of clay into the starch polymer matrix, the G20-NaMMT10 nanocomposites revealed a mean value of 92.5 $\mathrm{MPa}$ for hardness and $1888 \mathrm{MPa}$ for the elastic modulus, indicating $12 \%$ and $133 \%$ increase, respectively. This improvement of the mechanical properties was further supported by SEM micrographs (Figures 4) which showed that the incorporation of clay nanoparticles into the polymer matrix (over the range of clay concentrations up to $10 \mathrm{wt} \%$ and glycerol concentration of $20 \mathrm{wt} \%$ ) has formed a more compact structure with a homogeneous dispersion of clay platelets within starch matrix.

Similar improvement has been observed by another work ${ }^{35}$, where the inclusion of $10 \mathrm{w} / \mathrm{w} \%$ of HNTs in Poly (lactic acid) matrix significantly improved the elastic modulus by $27 \%$ at indentation depth of $300 \mathrm{~nm}$. However, this inclusion revealed little improvement in hardness. This increase in modulus is in accordance with another work ${ }^{36}$, where PLA/ organo-modified montmorillonite (PLA/O-MMT) films were synthesized by solution casting method, and reported that the tensile elastic modulus increased by $42 \%$ with addition of $6 \mathrm{w} / \mathrm{w} \%$ of O-MMT. On top of that, another work ${ }^{37}$ reported that the dispersion of O-MMT was enhanced after incorporating chain extender into the PLA/O-MMT composites which were prepared by melt compounding led to better mechanical and barrier properties. A further comparison of conventional composite and nanocomposite films with increasing glycerol content, however, revealed a decrease in hardness and modulus of elasticity because of the weak hydrogen bonding interaction between starch chains and glycerol molecules.

In the case of G30-NaMMT0 conventional composites the hardness and elastic modulus from nanoindentation tests were $33.1 \mathrm{MPa}$ and $430 \mathrm{MPa}$, respectively, while for the G30-NaMMT10 nanocomposite samples the hardness and modulus of elasticity were found to be $40 \mathrm{MPa}$ and $500 \mathrm{MPa}$, respectively. The incorporation of $10 \mathrm{wt} \% \mathrm{NaMMT}$ clay into starch matrix containing higher concentrations of glycerol $(30 \mathrm{wt} \%)$ resulted in an insignificant improvement of mechanical properties of maize starch nanocomposite films. As it can be seen from Figure 9, the hardness and elastic modulus values were increased with decreasing the concentrations of glycerol from 20 to $30 \mathrm{wt} \%$ and increasing sodium montmorillonite clay from 0 to $10 \mathrm{wt} \%$. Films prepared with the same sodium montmorillonite clay content and lower glycerol concentrations exhibited higher values of hardness and elastic modulus than the films prepared with higher levels of glycerol. However, as shown in Figure 8, the mechanical properties of nanocomposite films deteriorated as the clay content was increased above $10 \mathrm{wt} \%$. The higher the clay content, the higher the tendency of nanofillers to aggregate in the starch polymer matrix, thereby deteriorating mechanical properties of nanocomposite films. As discussed previously, SEM/EDX analysis revealed an inhomogeneous 

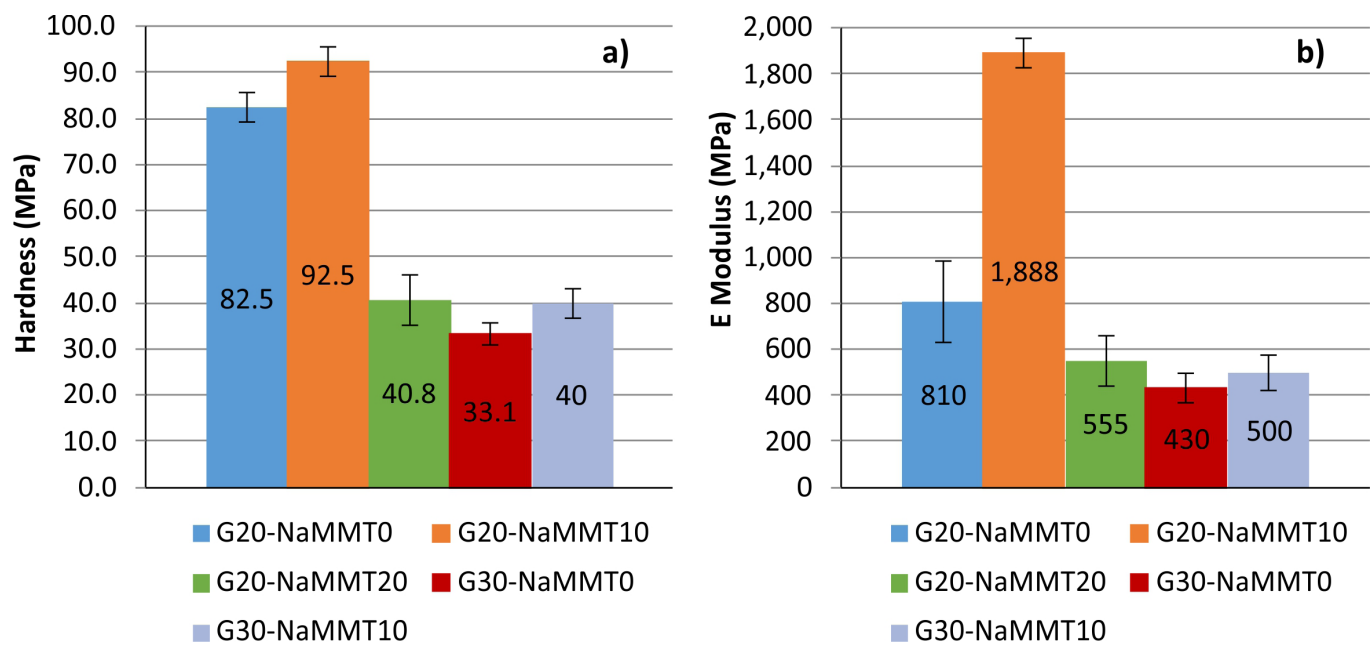

Figure 8. Hardness and modulus of elasticity from nanoindentation tests.
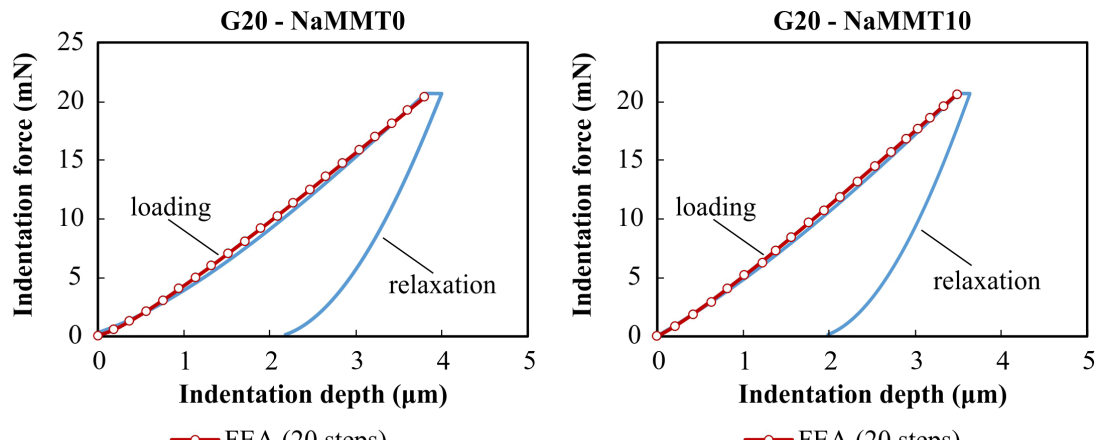

$\multimap$-FEA (20 steps)

_ Experimental nanoindentation
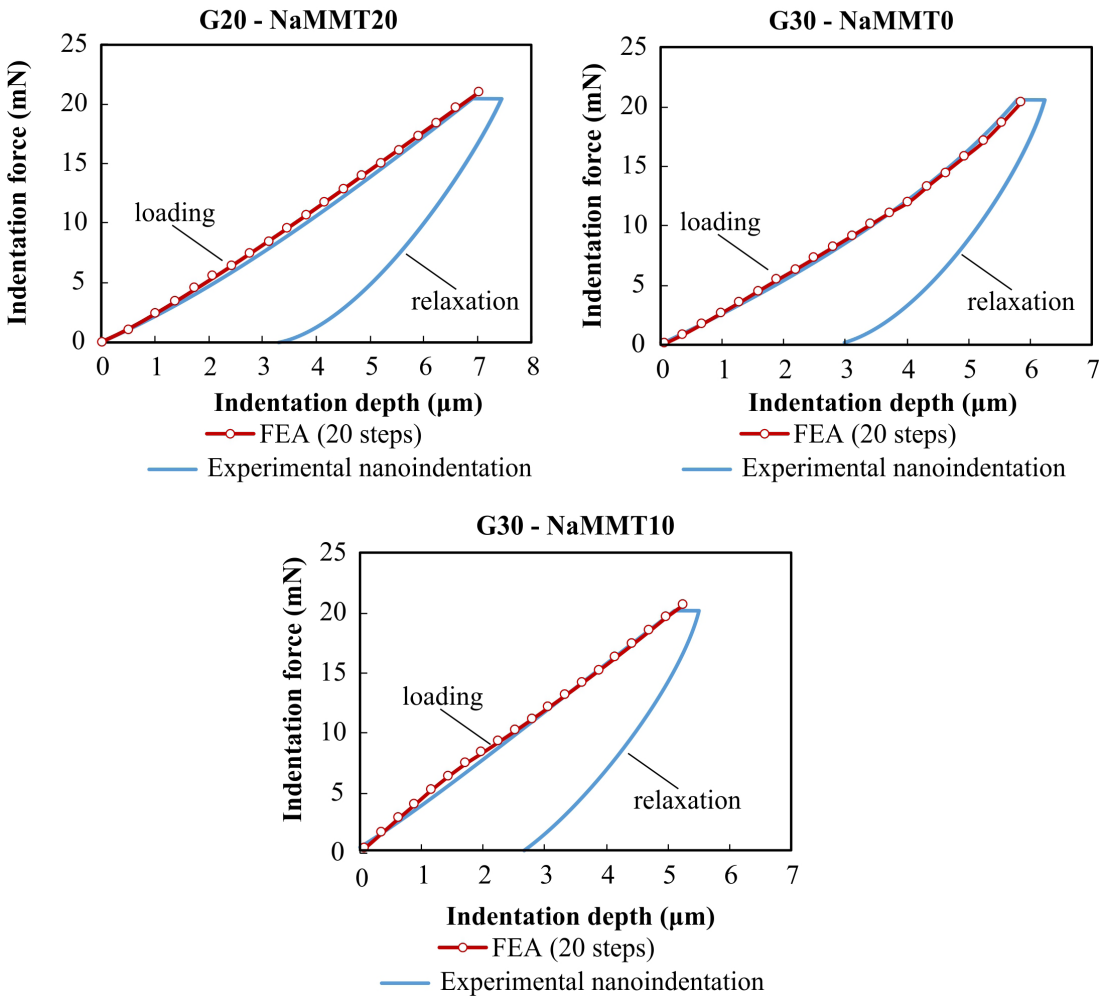

Figure 9. Comparison between FEA-determined and experimental nanoindentation tests. 
a) G20 - NaMMT0

von Mises Equivalent Stress, $S_{\text {eqv }}[\mathrm{MPa}]$ at stage 4

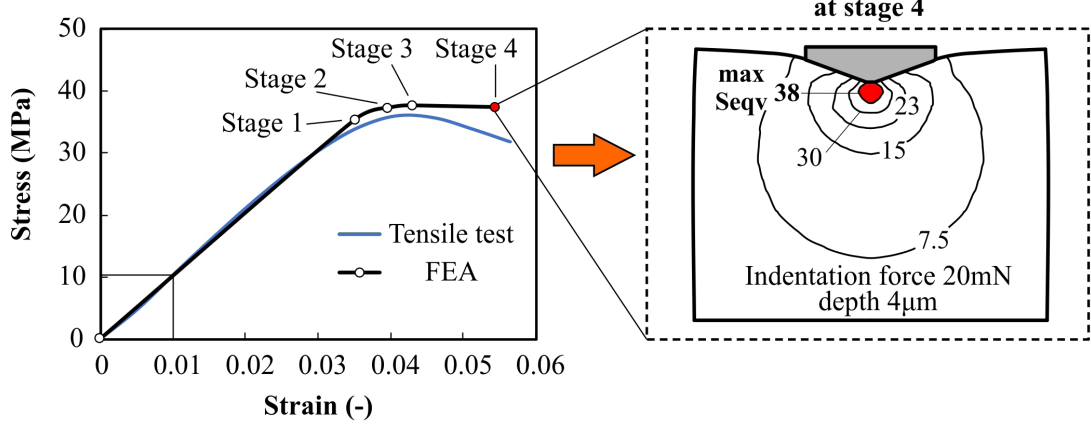

b) G20 - NaMMT10

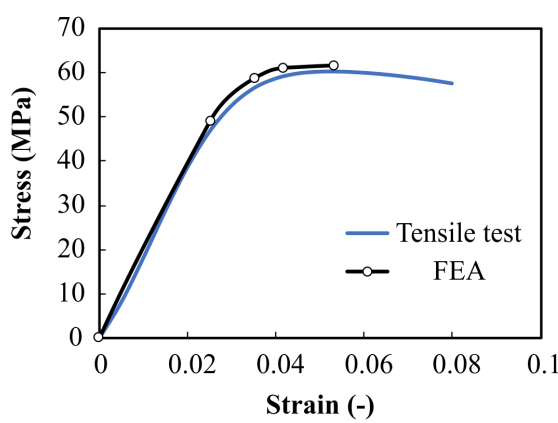

c) G20 - NaMMT20

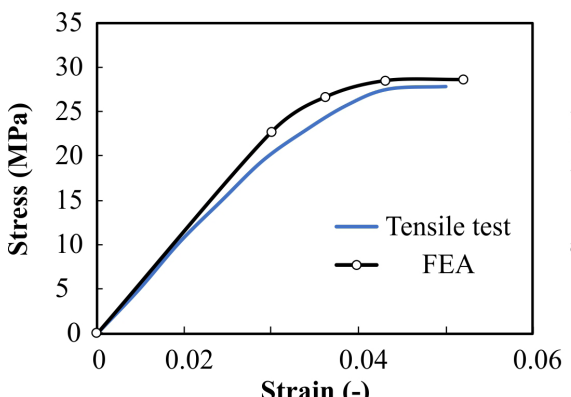

d) G30 - NaMMT0

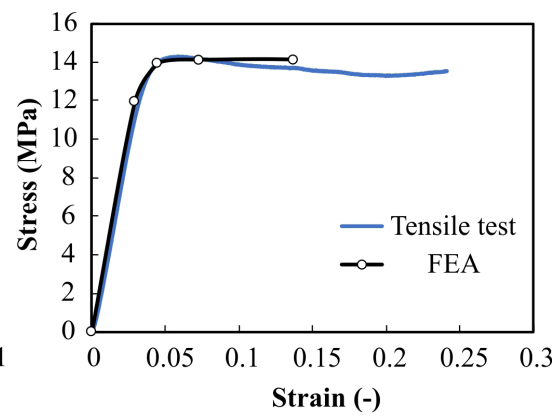

e) G30 - NaMMT10

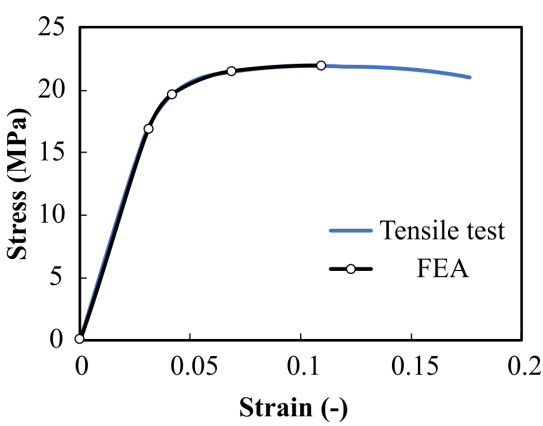

Figure 10. Comparison of the stress-strain curves from FEA simulation with the tensile tests.

distribution of clay platelets in the starch matrix with significant aggregation of nanoparticles occurred at higher clay loading levels $(20 \mathrm{wt} \%)$ that resulted in easily fractured materials with poor mechanical properties. From the analysis above, it can be concluded that the best values were reached with sodium montmorillonite nanocomposites content of about $10 \mathrm{wt} \%$ at glycerol concentration of about $20 \mathrm{wt} \%$.

Nanoindentation test results are presented by the typical indentation load-penetration depth curves of the maize starch nanocomposite films, as shown in Figure 9. It is obvious from Figure 9 that the maximum indentation depths range approximately between 3.59 to $7.47 \mu \mathrm{m}$. The load-depth curves of the films indicated creep phenomenon of the specimens at peak load of $20 \mathrm{mN}$. In the case of G20-NaMMT20 films, greater plasticity was revealed, with the G20-NaMMT10 samples exhibiting higher elastic recovery than other composites. In Figure 9, finite element analysis (FEA) results of load-depth behavior are also presented, which demonstrate that there is a good agreement between the measured nanoindentation tests and the computationally generated curves in the case of a series of representative conventional composite and nanocomposite films.

Nanoindentation tests were applied to measure the hardness and modulus of elasticity of the films (shown in Figure 8) and were also used as input to FEA simulations of mechanical properties of the materials under study. The corresponding stress-strain curves of starch - based films were further obtained from the nanoindentation results through the FEA simulation method. As shown in Figure 10, there is a good correlation between the stress-strain curves from FEA simulation and tensile tests. For instance, the value of the elastic modulus (initial slope) for the G20-NaMMT10 was determined to be $810 \mathrm{MPa}$ and this is in agreement with another work ${ }^{18}$. Based on the findings it can be concluded that the FEA supported by experimental nanoindentation technique has shown to be a very effective method to characterize the mechanical deformation behavior of conventional composite and nanocomposite starch-based films. 


\section{Conclusions}

A series of conventional composite and nanocomposite maize starch - based films were developed by a solution mixing procedure with glycerol/water plasticizer containing sodium montmorillonite (NaMMT) clay as reinforcing filler. The instrumented indentation technique was used in this study to characterize the mechanical properties of starch bioplastic materials. Nanoindentation test results were presented by the typical indentation load-penetration depth curves of the obtained films. SEM micrographs with the x-ray mapping analysis of the cross section of the films have also confirmed that the incorporation of clay platelets into the starch polymer matrix over the range of clay concentrations up to $10 \mathrm{wt} \%$ has formed a more compact and homogeneous structure and improved the mechanical properties of the nanocomposite films, while the XRD patterns indicated an intercalated nanocomposite structure. The mechanical behavior of thermoplastic starch-based composite films was further investigated by combining the experimental indentation curves with Finite Element Analysis (FEA) simulations of indentation tests. The approach to simulate the nanoindentation tests by FEA resulted in a very good agreement with the experimental tensile test data. Thereby, it is concluded that the proposed indentation testing method has shown to be a very effective approach to characterize the elastic - plastic deformation behavior of the starch/clay nanocomposite films.

\section{Acknowledgements}

This research is co-financed by Greece and the European Union (European Social Fund- ESF) through the Operational Programme «Human Resources Development, Education and Lifelong Learning» in the context of the project "Strengthening Human Resources Research Potential via Doctorate Research" (MIS-5000432), implemented by the State Scholarships Foundation (IKY).

\section{References}

1. Vilgis TA, Heinrich G, Klüppel M. Reinforcement of Polymer Nano-composites: theory, experiments and applications. Cambridge, Reino Unido: Cambridge University Press; 2010.

2. Assael MJ, Antoniadis KD, Metaxa I, Tzetzis D. Measurement of the enhancement of the thermal conductivity of an epoxyresin polymer when reinforced with glass fibres and/or carbon multi-walled nanotubes. J Chem Eng Data. 2009;54(9):2365-70.

3. Mansour G, Tsongas K, Tzetzis D. Modal testing of epoxy aramid-carbon fiber hybrid composites reinforced with silica nanoparticles. J Reinf Plast Compos. 2016;35(19):1401-10. http://dx.doi.org/10.1177/0731684416652488.

4. Tzetzis D, Tsongas K, Mansour G. Determination of the mechanical properties of epoxy silica nanocomposites through FEA-supported evaluation of ball indentation test results. Mater Res. 2017;20(6):1571-8.

5. Mansour G, Tsongas K, Tzetzis D, Tzikas K. Dynamic mechanical characterization of polyurethane/multiwalled carbon nanotube composite thermoplastic elastomers. Polym Plast Technol Eng. 2017;56(14):1505-15.

6. Tsongas K, Tzetzis D, Mansour G. Mechanical and vibration isolation behavior of acrylonitrile-butadiene rubber/multi-walled carbon nanotube composite machine mounts. Plast Rubber Compos. 2017;46(10):458-68.
7. Tsongas K, Tzetzis D, Karantzalis AE, Banias G, Ahmadkhaniha D, Zanella C, et al. Microstructural, surface topology and nanomechanical characterization of electro-deposited Ni-P/SiC nanocomposite coatings. Appl Sci (Basel). 2019;9(14):2901-16. http://dx.doi.org/10.3390/app9142901.

8. Klonos P, Papadopoulos L, Tzetzis D, Kyritsis A, Papageorgiou G, Bikiaris D. Thermal, nanoindentation and dielectric study of nanocomposites based on poly(propylene furanoate) and various inclusions. Materials Today Communications. 2019;20:100585. http://dx.doi.org/10.1016/j.mtcomm.2019.100585.

9. Mansour M, Tsongas K, Tzetzis D. Measurement of the mechanical and dynamic properties of 3D printed polylactic acid reinforced with grapheme. Polym Plast Technol Eng. 2019;58(11):1234-44. http://dx.doi.org/10.1080/03602559.2 018.1542730 .

10. Mansour M, Tsongas K, Tzetzis D, Antoniadis A. Mechanical and dynamic behavior of fused filament fabrication $3 \mathrm{D}$ printed polyethylene terephthalate glycol reinforced with carbon fibers. Polym Plast Technol Eng. 2018;57(16):1715-25.

11. Thomsen MR, Tamke M, Gengnagel C, Faircloth B, Scheurer FR, editors. Modelling behaviour: design modelling symposium. USA: Springer; 2015. https://doi.org/10.1007/978-3-319-242088.

12. Ashby MF. Materials and the environment: eco-informed material choice. Oxônia: Butterworth-Heinemann Ltd.; 2009. p. 594-595.

13. Pacheco-Torgal F, Labrincha JA, Diamanti MV, Yu CP, Lee HK. Biotechnologies and biomimetics for civil engineering. USA: Springer; 2015.

14. Lyons A. Materials for architects and builders. USA: Elsevier; 2010.

15. Madhumitha G, Fowsiya J, Mohana-Roopan S, Kumar Thakur V. Recent advances in starch-clay nanocomposites. Int J Polym Anal Charact. 2018;23(4):331-45. https://doi.org/10.1080/102 3666X.2018.1447260.

16. Van Soest JJG, Knooren N. Influence of glycerol and water content on the structure and properties of extruded starch plastic sheets during aging. J Appl Polym Sci. 1997;64:1411-22. http:// dx.doi.org/10.1002/(SICI)1097-4628(19970516)64:7.

17. Pandey JK, Singh RP. Green nanocomposites from renewable resources: effect of plasticizer on the structure and material properties of clay-filled starch. Starke. 2005;57(1):8-15.

18. Zoumaki M, Tzetzis D, Mansour G. Development and characterization of starch - based nanocomposite materials. IOP Conf Ser: Mater Sci Eng. 2019;564:012037. http://dx.doi. org/10.1088/1757-899X/564/1/012037.

19. Mansour G, Tzetzis D. Nanomechanical characterization of hybrid multiwall carbon nanotube and fumed silica epoxy nanocomposites. Polym Plast Technol Eng. 2013;52(10):105462. http://dx.doi.org/10.1080/03602559.2013.769581.

20. Mansour G, Tzetzis D, Bouzakis KD. A nanomechanical approach on the measurement of the elastic properties of epoxy reinforced carbon nanotube nanocomposites. Tribology in Industry [serial on the Internet]. 2013;35(3):190-199. Available from: https:// www.researchgate.net/publication/268764653

21. Tzetzis D, Mansour G. Nanoindentation, compression and fractural characterisation of highly dispersed epoxy silica nanocomposites. J Reinf Plast Compos. 2016;35(7):541-55. http://dx.doi.org/10.1177/0731684415623653.

22. Tzetzis D, Mansour G, Tsiafis I, Pavlidou E. Nanoindentation measurements of fumed silica epoxy nanocomposites. J Reinf Plast Compos. 2013;32(3):160-73.

23. Lichinchi M, Lenardi C, Haupt J, Vitali R. Simulation of Berkovich nanoindentation experiments on thin films using finite element method. Thin Solid Films. 1998;312:240-8.

24. Mansour G, Zoumaki M, Marinopoulou A, Raphaelides S, Tzetzis $\mathrm{D}$, Zoumakis N. Investigation on the effects of glycerol and clay contents on the structure and mechanical properties of maize 
starch nanocomposite films. Starch. 2020;72(3-4):1900166. https://doi.org/10.1002/star.201900166.

25. Mansour G, Zoumaki M, Marinopoulou A, Tzetzis D, Prevezanos M, Raphaelides S. Characterization and properties of non-granular thermoplastic starch - clay biocomposite films. Carbohydr Polym. 2020;245:116629. https://doi.org/10.1016/j. carbpol.2020.116629.

26. Müller P, Kapin E, Fekete E. Effects of preparation methods on the structure and mechanical properties of wet conditioned starch/montmorillonite nanocomposites films. Carbohydr Polym. 2014;113:569-76. http://dx.doi.org/10.1016/j.carbpol.2014.07.054.

27. ASTM: American Society for the Testing of Materials. Standard test methods for tensile properties of thin plastic sheeting. West Conshohocken: ASTM; 2012.

28. Oliver WC, Pharr GM. An improved technique for determining hardness and elastic-modulus using load and displacement sensing indentation experiments. J Mater Res. 1992;7(6):156483. http://dx.doi.org/10.1557/jmr.1992.1564.

29. Bouzakis KD, Michailidis N, Erkens G. Thin hard coatings stress strain curve determination through a FEM supported evaluation of nanoindentation test results. Surf Coat Tech. 2001;142(144):102-9. http://dx.doi.org/10.1016/S02578972(01)01275-0.

30. Chen BQ, Evans JRG. Thermoplastic starch-clay nanocomposites and their characteristics. Carbohydr Polym. 2005;61(4):455-63.

31. De Carvalho AJF, Curvelo AAS, Agnelli JAM. A first insight on composites of thermoplastic starch and kaolin. Carbohydr Polym. 2001;45:189-94.
32. Todica M, Nagy EM, Niculaescu C, Stan O, Cioica N, Pop CV. XRD investigation of some thermal degraded starch based materials. J Spectrosc. 2016;9605312. https://dx.doi. org/10.1155/2016/9605312.

33. Gutiérrez TJ, Ollier R, Alvarez VA. Surface properties of thermoplastic starch materials reinforced with natural fillers. In: Thakur V, Thakur M, editors. Functional biopolymers. Cham: Springer; 2018. Chap. 5, p. 131-58. Springer Series on Polymer and Composite Materials. https://doi.org/10.1007/978-3-31966417-0_5.

34. Shashi K, Wan PZ, De Leon JE, Mosher C, Colonna W, Keener KM. High-voltage atmospheric cold plasma treatment of different types of starch films. Starch. 2017;69(11-12):1700009. https:// doi.org/10.1002/star.201700009.

35. De Silva R, Pasbakhsh P, Goh K, Chai S-P, Chen J. Synthesis and characterisation of poly (lactic acid)/halloysite bionanocomposite films. J Compos Mater. 2014;48(30):3705-17. http://dx.doi. org/10.1177/0021998313513046.

36. Chang J-H, An YU, Sur GS. Poly(lactic acid) nanocomposites with various organoclays. I. Thermomechanical properties, morphology, and gas permeability. J Polym Sci, B, Polym Phys. 2003;41:94-103.

37. Najafi N, Heuzey MC, Carreau PJ. Polylactide (PLA)-clay nanocomposites prepared by melt compounding in the presence of a chain extender. Compos Sci Technol. 2012;72:608-15. 